\title{
The Predicament of Specialized Villages and Its Solutions: A Case Study of Zhe-Village
}

\author{
Zhijun Liu \\ Zhejiang University \\ Jiansheng Chen \\ Zhejiang University of Finance and Economics
}

\begin{abstract}
Due to high competition in the same trade, residents in a specialized village become "homogeneous without shared interest". Based on a case study of Zhe-Village, this paper describes the competition and conflicts inside specialized villages, as well as attempts at reconciliation. We find traditional measures of reconciliation, e.g. through personal relationship, community elites or their local government, to be fundamentally divergent from the economic aim of specialized villages, hence the limited effectiveness. Establishing a trade association is a possible solution to the predicament of Zhe-Village, but the lack of shared interests and inaction of the local government, combined with the attitude and distorted knowledge of villagers, hamper the founding of a trade association. To overcome these obstacles, specialized villages need rules of market competition, government support and updated knowledge. In this process, social integration may reappear in specialized villages.
\end{abstract}

\section{INTRODUCTION}

The notion of "Specialized villages" refers to the villages where people undertake the same profession or similar economic activities; thus gradually the villages gain the recognized reputation as specialized production bases. Since the era of reform and opening up, industrialization has spread to rural areas and specialized villages have appeared in many parts of China, especially the developed provinces in eastern China. According to data of "Farmer's Daily" (Nong Min Ri Bao), there were 41,293 specialized villages in China by the end of 2006, with 19,705,800 rural families involved; and for the involved rural families, net annual income per capita reached 4,560 yuan, $27 \%$ higher than the national average of rural population ( $\mathrm{Li}$, 2007).

For more than two decades, Zhejiang has had the highest income per capita among all provinces in China. Zhejiang is also an important region for the development of specialized villages, which can be found in almost every county of Zhejiang Province. These villages mainly specialize in light industry and agricultural products, e.g. textile products, clothing, toys, low- 
voltage electrical apparatus, hardware, food, etc. However, this kind of production usually requires simple technological knowledge and is easy to replicate, so that factories easily agglomerate in rural areas.

Compared to the traditional rural communities, specialized villages have some unique characteristics. Traditional rural communities are "acquaintance societies", in which interpersonal relationship is based on "differential order", and ties of blood, origin and relationship have natural functions of integration (Fei, 1998: 24-30). In specialized villages, however, competition within the same trade often leads to "cost-benefit" calculations, undermining "mutual understanding" natural to traditional community life. Life-based relationships and production-based relationships intertwine between each other and become complex and tense.

Then how do organically-integrated traditional communities react to highly competitive markets? What spontaneous attempts will they undertake to resolve problems brought by the new situation? What difficulties will occur in these attempts? How will they deal with these difficulties? How would these difficulties be best dealt with? These questions are all worthy of academic inquiries.

There has already been some Chinese academic scholarship paying attention to specialized villages. Much research has focused on the types, features and conditions $(\mathrm{Xu}, 1987$; $\mathrm{Li}, 1996$; Ning, 2009) or the formation and evolution ( $\mathrm{Li} \&$ Luo, 2009) of specialized villages; the specialized villages' force for rural economic development (Sun, 1982; Zhou \& Chen, 1994) and force for rural social construction (Qi, 2006), as well as building of specialized villages (Ma, 2000), etc. Other research (Yang, 1995; Zhao, 2005) examined the problems in the development of specialized villages, but primarily through the perspective of economy and market, such as mal-organizations, lagged-behind markets, lack of fiscal input, lack of capital, lack of technology, over-regulation, etc as well. Little emphasis has been placed on the market's impact on rural communities.

Based on a case study of a specialized village in Shaoxing, Zhejiang Province (Zhe-Village in this manuscript), we intend to describe the situation of competition and conflict in specialized villages, and the attempts to intervene in internal conflicts and build up new integration mechanisms; meanwhile, we intend to analyze the effectiveness and related problems along with these attempts, trying to put forward possible solutions to these problems. Data used in this paper was mainly collected by doing fieldwork in Zhe-Village from 2007 to 2010. By reading chorography, village chronicles and statistics, we got the information related to village history, clan and household system, economic development, social structure, etc. By doing intensive interviews with incumbent and retired officials, entrepreneurs, workshop owners, local elite and ordinary villagers, we got information about the competition and conflicts in Zhe-Village before and after it became a specialized village, as well as the attempts at reconciliation.

\section{OVERALL INFORMATION OF ZHE-VILLAGE}

\section{Historical and Geographical Background}

Zhe-Village is a specialized village in the center of Zhejiang Province. It is over twenty kilometers to the west of Shengzhou District, Shaoxing City. Though Zhe-Village is surrounded by mountains, the transportation is quite convenient with less than half an hour's drive from several developed counties such as Dongyang, Yiwu, Shaoxing, Zhuji and Xinchang. The village can be dated back to the Song Dynasty and is the birthplace to Xing's family of West Shan County (an ancient county). There are two major surnames in the village: Xing and Guo, 
respectively making up $70 \%$ and $20 \%$ of the village population. Because of Xing's complicated zong (clan) and fang (household) system, the Xings' openness to marriage with people with other surnames, and the post-1949 nationwide depression of the patriarchal clan system, the domination of a clan or a household in rural society can hardly be possible at Zhe-Village.

\section{Population and Economy}

During the period of our case study, Zhe-Village had 673 households, a population of 1,692, $758 \mathrm{mu}$ farmland and over 50 family operate factories. In 2010 the total income of Zhe-Village reached 70,000,000 yuan, net income per capita 14,000 yuan.

The predominant production of Zhe-Village is hose. ${ }^{1}$ Over 30 factories produce hose as the main product, and $60 \%-70 \%$ of all the households are involved in hose production. The hoses are mainly sold to drought-stricken areas in northern China, like Shandong, Shanxi and Hebei Provinces. These factories are not big in scale: the annual value of production of a typical one is around one million yuan, the bigger around five million, the smaller around a hundred thousand and the handicraft workshops are even smaller. Nevertheless, the total productivity of over 30 factories in the trade is considerable so that the hose business at Zhe-Village is widely known, even outside of Zhejiang Province.

\section{The Formation of a Specialized Village}

Zhe-Village began to grow up as a specialized village since 1978. In that year, a military cadre from Shanghai came up with the proposal of hose business during his visiting of his poor, post-Cultural Revolution hometown (Zhe-Village). With his help, the village-collective enterprise, led by village cadres, borrowed 8,000 yuan from richer villages, bought 8 machines for hose production and started up the Shengzhou Hose Factory. As an early bird which was technically supported by resources from Shanghai, the factory expanded very rapidly, until running into an unconquerable distress due to multiple reasons in 1988 when the deficit reached seven million yuan. In this situation, the village-collective enterprise was dissolved and the factory was divided among several individual villagers.

Therefore, over 10 family-own hose factories were founded at the same time. With the collective ownership turning into private ownership, the incentives for profit were instantaneously encouraged. Factory owners opened up markets and sought for new buyers, and the trade became immensely prosperous. Huge profits stimulated imitation from fellow villagers and another 20-30 family-owned hose factories were soon built. Thus Zhe-Village became a specialized village. In the middle and late 1990s, the Yellow River basin was ravaged by drought in successive years, making the hose business in Zhe-Village even more prosperous.

\section{ZHE-VILLAGE'S PREDICAMENT}

However, the hose business depends heavily on weather. The demand rises in drought and falls without drought. The demand goes highest when underground water can be pumped in drought. Zhe-Village's hose business was driven up by prolonged drought in northern China in the middle and late 1990s, but met a decrease in demand after 2000. Since 2000, hose production in Zhe-Village keep shrinking seriously with decreasing profit due to the following major reasons:

(1) Demand for hose decreased as drought in northern China eased. 
(2) As the number of hose factories in Zhe-Village increased, the overall production power rose so much that the sum of several factories' current output exceeds the total output of Zhe-Village years ago.

(3) Because hose production requires relatively simple technology and is easy to duplicate, similar hose factories mushroomed in nearby areas like Cixi and Yuyao when the demand was high. This quickly led to a saturation of productivity.

(4) Zhe-Village factories rarely developed new products or opened up new markets.

(5) Some factories moved out of Zhe-Village. Several bigger hose factories moved to the city center or town center. Some even moved to the place of hose buyers like Linyi in Shandong Province for example, reducing transportation cost and promoting their competitiveness.

In this situation, hose factories in Zhe-Village had no other choice except to lower their prices to keep their products salable. In 2006, profit per meter of hose was 0.05-0.1 yuan in the northern market, and 0.1-0.2 yuan in the southern market, which were much lower than profit of the middle 1990s. In the face of high competition, villagers began to compete for buyers. This competition immediately turned the quite village into one "full of quarrels." As disagreements accrued in Zhe-Village, hose factories started to undermine each other, grab customers of competitors, defame rival factories' reputations, find fault with each other, and sometimes even hire hatchet men to threaten competitors.

\section{ZHE-VILLAGE'S ATTEMPTS OF SOLUTION AND THEIR LIMITATIONS}

Since the above difficulties and chaos in the hose trade took place in a traditional village community with organic solidarity, there were many non-market factors in these seemingly economic activities. The traditional powers like personal relationships, local customs and local authorities still have important influence on the relationships among factories, and were taken as the first tools.

\section{Reconciliation through Personal Relationships}

Villagers usually tended to settle disagreements through verbal persuasion, especially those disagreements between relatives and friends. Typical lines of persuasion are like: "We are all relatives, and it does not mean anything to be like this"; "It is just a matter of a few yuan, (so) it is not worth it to hurt your relative, (and) perhaps you will need his/her help in future business"; "(One) should not lose one's conscience in doing things, or one will receive bad fortune"; "We are all relatives, what is this (disagreement) for anyway?"; "It does not really matter who they buy from-we are after all relatives - let us all budge a bit and let this go". Given the "face" of personal relationship, questions irrelevant to fundamental interests would usually be solved to some extent.

Nonetheless, as competition intensified and hose demand decreased, such propitiations through personal relationships could not settle further disagreements, and conflicts broke out now and then in Zhe-Village. The key problem in these conflicts was a complex entanglement of inter-personal relationships as well as benefits. When interests did not conflict too much, peace could usually be maintained; when competition got stronger, interests obviously began to conflict. As one villager said, "others sell more means that I sell less". At this time, their relationship became a zero-sum game. 
Profits are calculable in market economy, but not personal relationships since relationships can be largely traced back to cultural traditions and organic connections of a traditional community. Incalculable blood or social relationships could hardly continually propitiate calculable conflicts, and conflicts would inevitably grow out of disagreements.

\section{Reconciliation through the Authority of Community Elites}

Failing in making use of power of personal relationships, the hose producers at Zhe-Village turned to the village's Party Secretary and Committee Director, two figures being in charge of the village and regarded as local authority. Members of Zhe-Village's Party Branch and of Villagers' Committee (Cun Wei Hui) took a major role in setting up the old collective hose factory at the end of 1970s, by building up the business connections and exploring the market for the collective enterprise. It offered them both good connections outside the village and high prestige inside the village. Meanwhile, although Xing was the major surname in Zhe-Village, their patriarchal power was weak and could not challenge village leaders. Therefore, the village's Party Secretary and Committee Director had always been respectful and decent men, winning trust from many fellow villagers. The two figures' intervention in disagreements could usually help propitiation. Many disagreements were resolved by the Party Sectary and Community Director, especially in the early years.

However, new problems emerged as the conflicts advanced further, which were mainly expressed in two aspects. On the one hand, "differential order" in an acquaintance community and factions still existed. For villagers, the Party Secretary and Community Director were not always fair. According to some villagers, "We are all relatives, but anyway some are closely related, some are not", "Those who have a better relationship with the Community Director always benefit more". More importantly, on the other hand, the village cadres themselves are the heads of hose production factories. Regarded as competitors playing as judges, their indifference and even integrity were inevitably cast doubt on. Some villagers spoke out straightly saying "The Party Secretary and the Village Head (the more common name for "Community Director") run factories themselves. They are better connected to higher leaders and they surely benefit a lot from these connections. Perhaps (some of) our connections (to buyers) have been taken away by them." In other words, the coordinative ability of village elites was often very limited.

\section{Reconciliation through Local Government}

When the neutrality of village elites was challenged, some of the villagers sought intervention and arbitration from the township level and even from the municipal government. No matter how effectively the higher government intervened to help settle disagreements, some of the following predicaments developed. The first problem was the inviter. If both parties were inviters, the government's intervention would usually work out well; if not, the initiating side would be suspected of being in an alliance with the government and this would undermine the credibility of the intervention. The second problem was the risks. Tax evasion was almost a universal strategy manipulated in the small factories of Zhe-Village, while the government probing into trade matters usually meant the risk of exposure of tax evasion and other gray activities. One factory owner from Zhe-Village spoke with frankness, "If they (the officials) come and any one discloses the problems - none of us is clean - it will all be over for us. Small factories like ours will fail inspections by any of government branches. Each and every factory here has problems including pollution, tax, disqualified products, etc. If not properly handled, it will all be over." Even if the government settled the disagreement with the consent of all 
villagers, the cost was high; not to mention that conflict would break out again if any side felt unsatisfied with the intervention result.

\section{Limitation of the Above Measures: Deviation from the Aim of Economic Development}

Inside a specialized village with increasingly complicated interpersonal relationships and interests, the attempts to settle disagreements through personal relationships, community elites or the higher government would always encounter a bottleneck, since these measures are fundamentally different from the aim of the specialized village - to profit from the economic market.

For many cases of interventions, maintaining the current order in Zhe-Village was given much more priority than providing a set of rules or a platform for negotiation or bargaining. In reconciliation through personal relationships, the arbitrary nature is apparent. However in reconciliation through village leaders or local government, although government officials are usually assumed to have a neutral standing, they tend to "control" disagreements rather than "settle" them, which often prevents more long-term solutions. The internal disagreements within specialized villages such as Zhe-Village are usually commercial ones, which call for two-way bargaining to be fully settled. Hence, the reconciliation through authority of village leaders or local government turns out to be more and more unsatisfactory.

\section{WHY NOT TRADE ASSOCIATIONS?}

Since the disagreements cannot be fully settled through traditional measures (i.e. through personal relationships, village elites or the local government), what can be the new solution for settling disagreements and overcoming predicaments in the specialized villages such as ZheVillage?

According to some general experience gained from the other places, the first choice in bringing order to same-industry competition is to set up a trade association. The trade association can help prevent cutthroat competition, stabilize market order, integrate resources and safeguard interests of the entire trade. For example, some factory owners propose to build up a trade association in resemblance to that of cheap-lighter factories in Wenzhou. This proposal, however, did not gain much support from Zhe-Village. Why?

\section{The Villagers' Narrative}

According to the Committee Director Xing, they had considered setting up a trade association to prevent Zhe-Village factories from undermining each other and lowering prices to cutthroat levels; however they found great difficulties in realizing this idea. In his analysis, there were mainly five difficulties in setting up a trade association.

(1) Reluctance and boycott by the bigger factories in Zhe-Village. They feared possible damage to their interests after a trade association was set up, especially the possibility that their customer resources would be shared. In their words, "Isn't this forcing me to share my benefits with others?"

(2) The payment of full-time staff in the trade association. Most of factory owners thought hiring the full-time staff would be a waste of money.

(3) Most factory owners had their private connections to get mortgages from banks, to benefit from favorable policies or to evade taxes. It would be less "convenient" under the supervision of a trade association. 
(4) To merge factories into a group ${ }^{2}$ would require large investments and development of new products, which would be rather risky. Villagers prefer "safer" business.

(5) No one was willing to take the responsibilities. Only the Secretary Branch and the Villagers' Committee had the ability to set up a trade association, but they found more risks than potential benefits. Moreover, members of the Secretary Branch and the Villagers' Committee owned factories themselves and were afraid that their interests might be undercut.

Our interviews showed that these five reasons, more or less, were prevalent in the ideology of Zhe-Villagers. Another Mr. Xing, ${ }^{3}$ who was once a government official, said something more:

"We all know that founding a trade association has its benefits, but we worry it may be independent of government control. Furthermore, the bigger factories will certainly take leading positions in the trade association, making the smaller factories more disadvantaged."

"The town-level government is also facing a dilemma in this question. The state asks us (the town-level government) to take less control. And the result may not be good if we intervene because if we intervene, the villagers will believe that we intervened for our own interests, so we will create a difficult situation. Moreover, if we do it (set up the trade association), the villagers will see it as a governmental order that has to be executed. For things like this, we will not do it if the villagers have not asked us to. It is a risky thing, and we fear the consequences of blowing it up."

"On the other hand, the village cadres usually have the ability to deal with the disagreements and conflicts. Of course, this is not always the case. If money is part of the problem, the village cadres can do nothing. So as you can see today, the two factories there are disputing again. Conflicts like this reappear time after time, and it is very difficult for village cadres to do something."

\section{Analyzing the Reasons}

Our field survey, along with the villagers' narratives, demonstrate that the reason why the trade association cannot be set up can be interpreted as the lack of social foundation of the following facets:

\section{The Lack of Shared Interests}

The core of "shared interests" should be common grounds of benefits and intertwined interests. There are two aspects of this: one is the identification of interests, i.e. the identification of the relatedness between individual interests and collective interests, and the identification with collective interests; the other is the rules conducive to connectedness of village members, i.e. collective punishment for violation of rules, insurance for income, etc.

In the case study of Zhe-Village, however, there was no explicit identification within the community when problems arose. Instead, villagers seek help from outside of the village, e.g. "use personal connections", and "find acquaintances inside the government". The result was, the factories in Zhe-Village were so accustomed to seeking outside help that identification within factories was even more weakened.

When factory-owners can find outside shelter to undermine their competitors without punishment, they surely will have no incentives to build alliance and no willingness to set up a 
trade association. More generally, setting up a trade association requires dealing with a balance of short-term and long-term interests. As Xuefeng He (2004) pointed out, however, due to the impact of market economy and diminishing influence of state power in villages, the expectations of villagers tend to be short-term rather than long-term. In sum, the lack of shared interests and the villagers' inclination to compete (rather than to cooperate) were the key reasons leading to the failure of setting up a trade association.

\section{Inaction of Local Government}

The attitude and standing of local government has great influence on the setting up of regional trade associations. If we call the lack of shared interests a problem of social identification; similarly, we can call the attitude of local government a problem of political identification.

For the local government, founding a trade association will have multiple implications. On the one hand, a trade association can help maintain the interests of the trade and help with the assignment of the local government, On the other hand, the autonomous nature of trade associations probably makes it difficult for the government to occupy an important role in founding trade associations. Currently, the performance of local government is predominantly judged by their higher government, which means the local government officials will try all their best to please their superiors in their work. No wonder that officials from the local government put stability-maintaining in the first place and do not worry about any potential troublesome consequences.

The interview with the former town-level Party Secretary Mr. Xing illustrates such inclinations of local government: "The state is always ordering us to take less control"; "For things like this, we will not do it if the villagers have not asked us to"; "It is a risky thing". Even if the local government is willing to found a trade association, they assume there is no proper way to carry it out. If the local government does it with administrative power, discontented villagers may report to the more superior level of government and put the local government in a difficult position. If they do it without administrative power, the villagers may not follow and care at all. Therefore, the local government usually prefers the least risky choice of inaction.

\section{Villagers' Misunderstanding of Trade Associations}

Our survey shows that Zhe-Villagers have very limited knowledge about trade associations and even have many misunderstandings.

Take the Committee Director for example: there were many times when he mistook a trade association for a corporation company. Although we explained the difference to him several times, he still mixed up these two concepts. The same misunderstanding was found in most of the villagers, because they kept mentioning the collective enterprise and its huge deficits. Due to this kind of stereotyped memories, setting up a trade association was equal to bringing individual factories back to collective ownership in the understanding of Zhe-Villagers, for whom it implied retreating along a bad road which was totally unacceptable.

Meanwhile, many villagers held the skeptical attitude about the functions of a trade association. For instance, many people raised questions like "does founding a trade association mean that we can create interest of the whole trade". In their opinions, setting up a trade association was no more than hiring idle staff and wasting of money. The widespread misunderstanding of Zhe-Villagers, along with the horrible memory of historical failure, significantly depressed the factory owners' will to found a trade association. 


\section{The Contentedness and Conservativeness of Factory Owners}

Most factory owners in Zhe-Village started their own enterprises to get rid of poverty. After they made some money, they began to hope for "stability". As the Committee Director put it, "better to play safe", the factory owners preferred making a thin profit safely rather than big money with risky options, such as expanding their enterprises, or setting up a trade association.

Such inclinations may differ from what we call entrepreneurship. Entrepreneurs are willing to take risks and attempt to pursue maximized profit, and have no problem in cooperating with their competitors. The factory owners in Zhe-Village, however, were satisfied with their current fortunes. This satisfaction, to a large extent, prevented their willingness and motivation to found a trade association to maximize their profits.

\section{SUMMARY AND DISCUSSION}

\section{Characteristics of Specialized Villages: Homogeneous Without Shared Interest}

Although villagers inside a specialized village are taking the same profession within the same trade, it does not automatically mean that there are shared interests among them. They are "homogeneous without shared interest", very different from "homogenous with shared interests" in traditional rural communities. In specialized villages, benefits are becoming the key factor of social integration.

In traditional rural communities, residents did similar farm work and lived similar lifestyles. They devoted most of their work to farming, their foundation of existence and development. Self-sufficiency was the main reason that the villagers had no necessity to compete with each other. In the long term, residents in the same village shared identical social customs, traditions and authorities on which their social intercourse was based. Meanwhile, the shared customs and traditions integrated the rural community both spiritually and materially.

Inside specialized villages, however, residents do not rely on lands for fortune, but on external markets. When the markets are saturated, the same-trade enterprises inside a specialized village find themselves in a "zero-sum game": the more you sell, the less I profit. In this situation, factory owners have to ensure their own interests with their own measures, e.g. developing connections with the government or the buyers, libeling other factories, etc. Intense competition and sometimes base measures undermine and impair relationships within villagers, making them "homogeneous without shared interest".

\section{Demand of Specialized Village: Social Integration Rather Than Social Stability}

Because specialized villages are "homogeneous without shared interest", and because there is no effective integration mechanism, the disagreements and conflicts inside specialized villages cannot be solved perfectly. Traditional measures surely continue to help mediation to some extent, but their intended goal of seeking internal stability makes it increasingly difficult to satisfy the demand of specialized villages. Toward to their further development, specialized villages call for social integration.

Social stability refers to the absence of severe disagreements or conflicts, or the appearance of a peaceful society; while social integration refers to harmony and accord among social systems, which promote overall efficacy and prevent consequences caused by lack of connections (Chen, 2004). In a specialized village closely connected with the market, the sametrade factory owners will inevitably compete with each other and have conflicting interests. Under such conditions, the building of social order requires constructive communication and 
interest sharing among the same-trade factory owners. Social stability, especially that based on reconciliation of interests, government's intervention or conventions, however, only requires a good control of undesirable incidents rather than well-coordinated social systems.

In sum, overall stability of a specialized village can be maintained via traditional measures, but village order based on social integration calls for a new approach. The core of this new approach is both to satisfy the interests of different factory owners and to defend the interests of the entire trade, at the same time. Founding a trade association in a specialized village may be a possible choice.

\section{Several Prerequisites for Establishing a Trade Association}

As our research showed, although trade associations can be effective measures to get rid of the predicament and bring about social integration in specialized villages, their establishing has met many difficulties including lack of shared interests, inaction of local government, as well as the attitude and knowledge of villagers. How to overcome these difficulties? Based on our case study of Zhe-Village, we propose that several steps must be taken before trade associations can be established.

\section{Strengthen Identification via Bringing Rules to Market Competition}

When the market is saturated, price is usually the only battlefield for similar products. Some factories may wage a price war to maintain their own standing, and it sometimes will lead to much lowered profitability and even a crisis of existence for many other factories in the same trade. Promoting the identification with fellow factories in the same trade can help prevent such lose-lose outcomes, and provide a good foundation for establishing a trade association at the same time. According to Durkheim, shared interests lead to cooperation in an organically integrated society (2000). Without such shared interests, it is impossible to found trade associations.

If competition within a trade is not a fair-play building upon the strict rule of law, it would be impossible to form unified identification of share interests. Taking the Zhe-Village case as an instance, hose producers took measures such as finding political shelter, fraud or tax evasion to ensure individual interests in the period of intensified competition, rather than abiding by the rules of competition to protect the interests of the entire trade. This is not only unfavorable to economic development of Zhe-Village, but also damaging to its social order. Hence, bringing in tough rules, especially the law, to market competition can significantly reduce illegal measures in competition, laying down a foundation for the formation of shared interests.

\section{Assistance and Guidance from the Government}

Although shared interests are the great driving power for the founding of autonomous trade associations, assistance and guidance from the government will still act as a key factor.

There are three ways in which government assistance is important for trade associations: First, in current China, organizations must register in accordance with "Regulation on Association Management", so governmental support will provide strong legitimacy of trade associations. Second, due to the competition among same-trade factories, it is difficult for them to be well coordinated automatically, and the government can initially act as a good coordinator. Third, implementing administrative policies would often require concerted actions from social organizations, and trade associations can be of great help in the process. In a word, the 
government should play an important role in the trade association, and will benefit from the mechanism of the trade association as well as from the win-win situation.

\section{Publicizing Knowledge on Trade Associations}

Growing up with inculcated "local knowledge" the breadth of vision and the configuration of ideology of most villagers are often limited even though many have turned from farm labor to private enterprises. The motivations to set up their own enterprises are to get rid of poverty, and they will focus on stability of their enterprises and individual life after achieving some basic goals, rather than the development of the enterprise or the entire trade. In their social interaction with the market and unfamiliar customers, they base their choices on personal trust rather than contracts and other institutionalized relationships.

In the case of Zhe-Village, a lack of knowledge about trade associations misled many villagers, including the elites such as the Committee Director, to equate a trade association with a corporate company or a collective enterprise. Before clearing this kind of misunderstanding, it is quite difficult to establish a trade association. Therefore, publicizing knowledge of trade associations is an important prerequisite for establishing one.

\section{CONCLUDING REMARKS}

A traditional community characterized by organic integration has to adopt and create some non-traditional, innovated measures to deal with the tough market competition and its side effects in the process of specializing.

Taking Zhe-Village as a typical case, the "shared understanding" natural to a traditional community has been collapsing in highly competitive same-trade competition. The new key factor for in-village relationships has become rational calculation of interests. Therefore, traditional routes of reconciliation, e.g. through personal relationships, community elites or the local government, are no longer fully capable of dealing with conflicts and predicaments in specialized villages. Thus new effective ways of communication and negotiation, including but not limited to, contract binding or trade association, should be introduced into the social life of specialized villages to strengthen internal integration and keep up comprehensive competitiveness. Toward establishing a trade association, fair rules for market competition, government support and popularized knowledge are prerequisites.

\section{Acknowledgement}

We are grateful to Professor Xiaozhang WANG, Daming ZHOU and two anonymous reviewers for their valuable comments on earlier versions of the paper. Special thanks to Judy Gay, Fangsheng ZHU and Yixin LI for refining and revising this article. Correspondence should be addressed to Zhijun LIU, Department of Sociology, Zhejiang University, Hangzhou, 310007, China (Email: liuzhijun@zju.edu.cn), and Jiansheng CHEN, Department of Sociology, Zhejiang University of Finance and Economics, Hangzhou, 310018, China (Email: chenjiansheng@163.com).

\section{ENDNOTES}

1. Mostly used for drought control rather than fire control. 
2. To Committee Director Xing's understanding, "trade association" and "group company" meant the same thing. This misunderstanding was commonly seen in residents of ZheVillage.

3. The father of Mr. Xing was a veteran cadre in revolution years and was a high-ranking official. Moreover, Mr. Xing was well educated and was once the Party Secretary of the town. Therefore, his words were somehow authoritative.

\section{REFERENCES}

Chen, J.S. (2004). The Integration between a Strong State and a Strong Society: Thoughts on Civil Society Theories. Wenzhou Forum, 19(4): 55-58.

Fei, X.T. (1998). Rural China \& Institution for Reproduction. Beijing: Beijing University Press.

Li, Y.L. (2007). Ministry of Agriculture Selects 150 Model Specialized Villages Each Year: Over 40,000 Specialized Villages by the End of 2006. Farmer's Daily, Sept. 28(1).

He, X.F. (2004). Cooperation among Farmers: Logic of Action in an Acquaintance Society. Journal of Huazhong Normal University. 43(1): 5-7.

Li, X.J., Luo, Q. Fan, X.S. (2009). A Study on the Formation and Evolution of Specialized Rural Villages. China Soft Science, 24(2): 71-80.

Li, X.H. (1996). Investigation and Thoughts on the Development of Specialized Villages. Agricultural Management Science, 12(1): 5-7.

Ma, X.J. (2000). Building up Specialized Villages with Creative Mechanism is Helping the Development of Mountainous Areas. Problems in Agricultural Economy, 21(12): 47-49.

Ning, J. (2009). A Research on Specialized Villages in Guangxi Province. Journal of Nanning Vocational College, 14(1): 65-68.

Qi, S.H. (2006). The Effect of Specialized Villages in Constructing the Harmonious New Rural Areas. Economic Forum, 20(24): 129, 138.

Sun. H.Z. (1982). Specialized Households and Specialized Villages Accelerate Rural Economic Development. Rurual Economic Problems, 3(4): 65.

Durkheim, E. (2000). The Division of Labor in Society. Shanghai: Sino United Publishing, Co Ltd.

Xu, Z.H., Shi, H.J. (1987). A Brief Discussion on Emerging Specialized Villages in Rural Reforms. Gan River Economy, 8(4): 29-30.

Yang, H.X. (1995). Thoughts on Specialized Households and Specialized Villages in Yunnan Province. Journal of Yunnan Institute of Nationalities, 13(4): 13-16. 
Zhao, P. (2005). Policy Research on Specialized Villages in Harbin. Commercial Research, 48(13): 98-99.

Zhou, H.W. Chen, Q.S. (1994) A Good Model to Promote Rural Living Standards: Investigation and Thoughts on "One Village, One Product" Specialized Villages. Rural Development Studies, 9(2): 66-67. 